\title{
Effect of Mycoplasma on Interferon Production and Interferon Assay in Cell Cultures
}

\author{
D. ARMSTRONG 1 AND K. PAUCKER \\ Virus Laboratories, Children's Hospital of Philadelphia, and School of Medicine, University of Pennsylvania, \\ Philadelphia, Pennsylvania
}

Received for publication 18 March 1966

\begin{abstract}
Armstrong, D. (The Children's Hospital of Philadelphia, Philadelphia, Pa.), AND K. PAUCKer. Effect of mycoplasma on interferon production and interferon assay in cell cultures. J. Bacteriol. 92:97-101. 1966.-The influence of mycoplasma on the production and action of interferon was studied in cultures of both $L$ and human embryonic kidney (HEK) cells. Mycoplasma hominis 1, the Negroni agent, and the F12 mycoplasma were used for infection of $\mathrm{L}$ cells, and $M$. hominis 1 and $M$. pneumoniae for inoculation of HEK cells. All strains were capable of multiplication in the culture systems employed. None produced detectable levels of interferon, and responsiveness of the cells to induction of interferon by virus remained unaltered. Infection with mycoplasma did not impair the sensitivity of the cells to the action of interferon, nor was the replication of vesicular stomatitis virus noticeably diminished.
\end{abstract}

The inhibition of certain viruses in tissue cultures has previously been associated with the presence of mycoplasma $(1,3,13,15)$. This effect has been attributed to the depletion of a metabolic constituent in the medium for which the inhibited virus had an absolute requirement (13), to changes in $p \mathrm{H}$ unfavorable to viral replication (1), or to factors not otherwise specified. Inasmuch as several nonviral inducers are known to elicit the formation of interferon in tissue cultures as well as in animals (7), it appeared possible that interferon might be implicated in the observed viral suppression by mycoplasma. Such an effect could be mediated by mycoplasma-induced interferon itself, or by an enhanced interferon response to viral infection. Interferon production by mycoplasma in tissue culture has not been described, but, according to a recent report, circulating interferon was induced in mice on intravenous inoculation of Mycoplasma pneumoniae (Stinebring and Youngner, personal communication). This study was undertaken to determine whether controlled infection of cell cultures of murine and human origins with different mycoplasmas per se results in the synthesis of interferon, and whether the susceptibility of the cells to viral induction of interferon, interferon action, and to viral infection is altered in any way.

${ }^{1}$ Present address: Memorial Sloan-Kettering Cancer Center, New York, N.Y.

\section{MATERIALS AND Methods}

Mycoplasma strains. M. pneumoniae strain $\mathrm{FH}$ and the Negroni agent were obtained from L. Hayflick, Wistar Institute, Philadelphia, Pa. The Negroni agent, isolated from tissue culture inoculated with human leukemic material (10) and subsequently identified as a mycoplasma $(6,8)$, was reported to be related serologically to $M$. pulmonis, a rodent mycoplasma (5). M. hominis type 1, strain DC63, was obtained from Norman Somerson, National Institutes of Health, Bethesda, Md. The F12 mycoplasma, isolated from a pharyngeal fibroma (1) after passage through tissue cultures, has not been identified with other known human or animal strains of mycoplasma.

Growth of mycoplasma. The mycoplasma broth and agar medium used was that described by Hayflick (9). Titrations of supernatant tissue culture fluids were carried out in dilutions of $10^{-1}$ through $10^{-9}$ directly on agar. In the case of uninoculated controls, samples were first incubated in broth, followed by subculture on agar 1 week later to make sure that mycoplasma had not been inadvertently introduced in the course of the experimental period. Agar plates were inoculated with $0.01-\mathrm{ml}$ amounts of successive dilutions into each of four quadrants, and were read after 3, 7, 11, and 14 days of incubation. Tubes containing $2.5 \mathrm{ml}$ of broth were inoculated with $0.2-\mathrm{ml}$ amounts. Titers were expressed as $\log _{10}$ units per 0.1 ml of inoculum.

Tissue culture. $\mathrm{L}$ cells were grown in stationary cultures in a medium consisting of Scherer's maintenance solution, $60 \%$; medium $199,30 \%$; inactivated horse serum ( $56 \mathrm{C}, 30 \mathrm{~min}), 10 \%$; with penicillin and 
streptomycin in amounts of 100 units and $100 \mu \mathrm{g} / \mathrm{ml}$, respectively. Human embryonic kidney (HEK) cells were procured either commercially (Flow Laboratories, Rockville, Md.), in the form of tube cultures, or from the Virology Research Resources Branch of the National Institutes of Health, in the frozen state. These cells were thawed rapidly and planted in Blake bottles in the presence of Hanks-BME (Basal Medium Eagle, Hanks base) supplemented with $10 \%$ fetal calf serum, glutamine ( $2 \mathrm{~mm})$, non-essential amino acids $(0.2 \mathrm{~mm})$, and antibiotics as indicated above.

Viruses. For interferon production in L cells, the Victoria strain of Newcastle disease virus (NDV) was used. Sindbis virus was used to initiate interferon formation in HEK cells. The Indiana strain of vesicular stomatitis virus (VSV), propagated either in $\mathrm{L}$ cells or in chick embryo fibroblasts, was used as challenge agent in interferon assays.

Interferon. A standard preparation of L-cell interferon was obtained, and concentrated according to a method described earlier (11). The same procedure was followed to prepare a stock of HeLa-cell, interferon. In experimental groups of L-cell cultures, interferon was elicited by exposing fully grown monolayers in $75 \mathrm{~cm}^{2}$ Falcon plastic tissue culture flasks (Falcon Plastics Co., Los Angeles, Calif.) to NDV at an input multiplicity of about 100 . In HEK cells, grown in Blake bottles, interferon was induced by Sindbis virus at an input multiplicity of 2.5. Media were harvested $24 \mathrm{hr}$ later, and dialyzed against 100 volumes of $\mathrm{HCl} \mathrm{KCl}$ buffer $(p \mathrm{H} 2)$ for 1 to 3 days in the cold. The $p \mathrm{H}$ was returned to 7.4 by subsequent dialysis against $0.01 \mathrm{~m}$ phosphate-buffered saline, and all materials were stored in a refrigerator until titrations could be performed. Concentration, wherever indicated, was carried out by pervaporation or by ultrafiltration.

Assay of interferon. Titrations were carried out in the appropriate type of tube cultures of either $L$ or HEK cells. After refeeding with $1 \mathrm{ml}$ of fresh medium, duplicate tubes received serial twofold dilutions of interferon in 0.5-ml amounts. After $24 \mathrm{hr}$, the medium was again replaced and tubes were challenged with 0.2-ml inocula of VSV containing $50 \mathrm{TCID}_{50}$ for $\mathrm{L}$ cells and $500 \mathrm{TCID}_{50}$ for HEK cells. Final results were recorded on the second day when cells in controls were completely destroyed. Partial $(50 \%)$ destruction of the cell sheet was taken as the titration end point. Each assay was accompanied by a complete titration of VSV in control and in infected cultures to determine whether alterations in cellular susceptibility to the virus on progressive infection of the cultures with mycoplasma had occurred.

Experimental infection of $L$ cells with mycoplasma. Groups of $75 \mathrm{~cm}^{2}$ Falcon plastic bottles containing approximately $1.5 \times 10^{7}$ cells were inoculated with $0.5-\mathrm{ml}$ amounts of broth cultures of the following mycoplasmas: $M$. pneumoniae, the Negroni agent, $M$. hominis 1, and the F12 mycoplasma. Control bottles received the same amount of uninfected broth, and periodic examination revealed that they remained free from mycoplasma for the duration of the experiment. Immediately after inoculation, as well as 3, 7, and 10 days later, the following operations were per- formed. Samples were withdrawn and titrated on agar plates to assess the presence or the extent of multiplication of mycoplasma. Medium was collected and, after 10 -fold concentration $(\mathrm{v} / \mathrm{v})$ by pervaporation, was tested for the possible presence of interferon induced by mycoplasma. One bottle of each set was inoculated with NDV. The resulting interferon was collected $24 \mathrm{hr}$ later, and its titer was determined. The cell sheet of another bottle of each set was treated with trypsin $(0.25 \%$ trypsin, $7 \mathrm{~min}$ at $37 \mathrm{C})$. After centrifugation, the cells were suspended in fresh medium at a density of $5 \times 10^{5}$ per milliliter, and $1 \mathrm{ml}$ portions were inoculated into a series of culture tubes. After the cells had settled several hours later, they were used for assay of standard L-cell interferon to determine their status of sensitivity to the action of interferon. In addition, viable counts were performed on trypsin-treated cell suspensions by use of $0.1 \%$ trypan blue. In the course of the experimental period, each set of cultures was refed only once, and titers of mycoplasma were corrected for the amount removed.

Experimental infection of HEK cells with mycoplasma. Groups of Blake bottles containing approximately $10^{7}$ cells in full sheets were inoculated with 1 $\mathrm{ml}$ of a broth culture of $M$. hominis 1 , with $2 \mathrm{ml}$ of $M$. pneumoniae, or with mycoplasma-free broth. At the same time intervals as above, these bottles were handled like L-cell cultures, except that the cultures infected with $M$. hominis were processed on the 4th instead of the 3rd day, and viable-cell counts were not performed. Streptomycin was omitted from those cultures inoculated with $M$. pneumoniae, because this organism appeared to be sensitive to the antibiotic. Since it had proved difficult earlier to prepare secondary cultures of HEK cells, Blake cultures infected with mycoplasma could not be used directly to determine changes in sensitivity to the action of interferon. For that purpose, tubes of HEK cells were inoculated separately with $1 \mathrm{ml}$ amounts of $1: 50$ and $1: 25$ dilutions of the respective strains of mycoplasma. Periodic titrations disclosed that the growth of mycoplasma in these tubes was comparable with that in Blake bottles. No mycoplasmas could be isolated from uninoculated bottle and tube control cultures.

\section{Results}

Establishment and multiplication of mycoplasma. Of the four strains of mycoplasma used for infection of $\mathbf{L}$ cells, $M$. pneumoniae failed to establish itself and was, therefore, omitted from the tabulation of results. As can be seen from the left portion of Fig. 1, the Negroni agent as well as the F12 mycoplasma showed a continuous increase in titer over the 10-day experimental period. Examination of the cultures revealed slowly progressing cytopathic effects.(CPE) accompanied by increased acidity. These effects were marked in F12-infected cultures where they appeared on the 3rd day, whereas with the Negroni agent degeneration of cells was not clearly evident until the 10th day. More than $90 \%$ of the cells re- 


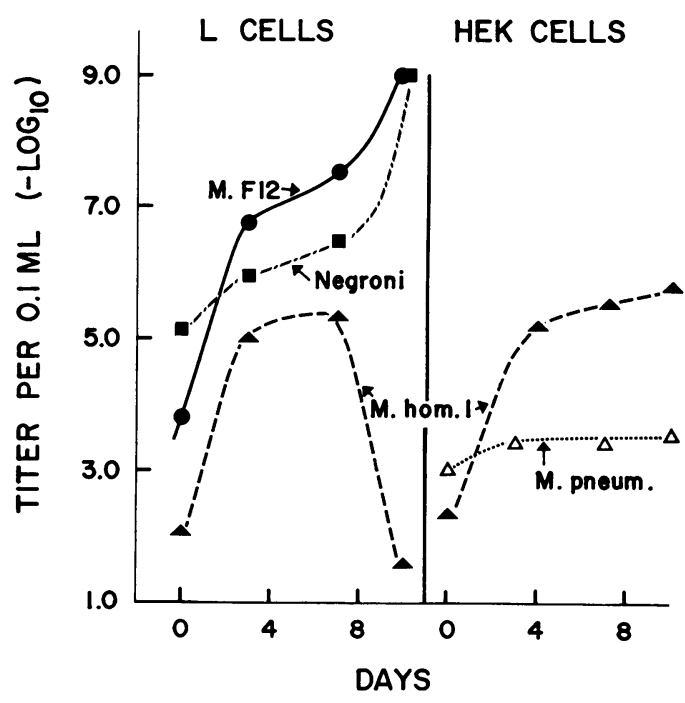

FIG. 1. Growth of mycoplasma in $L$ and human embryonic kidney cells.

mained viable throughout the incubation period (not shown in the figure), except for the last day when nonstaining cells declined to slightly below $80 \%$ of the total population. $M$. hominis 1 multiplied in $\mathrm{L}$ cells during the first few days, but then growth ceased abruptly. The cultures showed no visible CPE or increased acidity; counts of viable cells remained unchanged and were in excess of $90 \%$ of the total number of cells.

In HEK cells, the data presented in the righthand portion of Fig. 1 show a progressive multiplication of $M$. hominis 1 , whereas the increase in titer of $M$. pneumoniae was less marked. The growth of both strains of mycoplasma was not accompanied by readily recognizable $\mathrm{CPE}$ or changes in $p \mathbf{H}$.

Production of interferon. Table 1 combines the results obtained in $\mathrm{L}$ and HEK cells. In no instance did infection with any of the strains of mycoplasma result in the formation of detectable levels of interferon, even when media were concentrated 10-fold. Furthermore, the levels of virus-induced interferon in both types of cells were similar regardless of whether the cultures supported the multiplication of mycoplasma. The differences in titers of virus-induced interferon obtained in the two sets of HEK cells were presumably due to the fact that the experiments were performed at different times in two separate lots of HEK culture tubes.

Sensitivity to the action of interferon. The results of interferon titrations in mycoplasmainfected $\mathrm{L}$ and HEK cells are presented in Table 2. The activities of the two stock interferons were essentially unchanged throughout the duration of the experiment. The slight decline in interferon titer observed on the 10th day in two of three mycoplasma-infected cultures of $L$ cells may be accounted for by the general deterioration of the cells, since the reduction in titer was also seen in the uninfected controls.

Susceptibility to VSV. A total of 21 titrations of VSV accompanied the interferon assays in tube cultures of $\mathrm{L}$ and HEK cells infected with mycoplasma, as described, and in uninoculated con-

TABLE 1. Production of interferon in cultures of

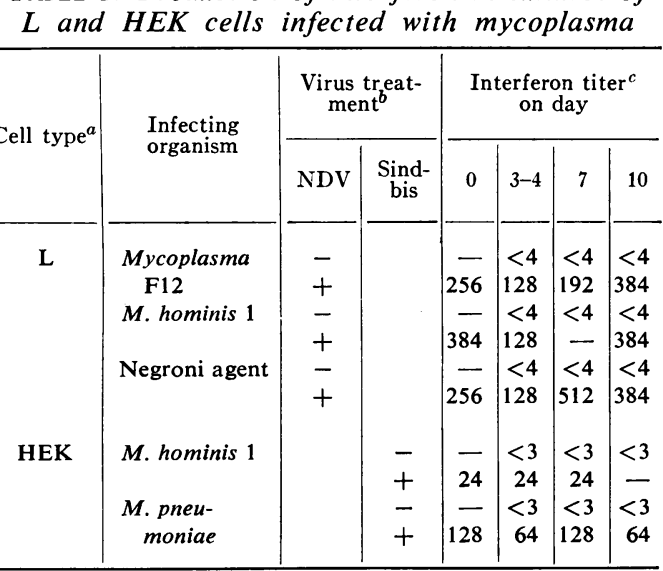

${ }^{a} \mathbf{L}$ group: media of cultures not exposed to NDV were concentrated 10 -fold $(\mathrm{v} / \mathrm{v})$ by pervaporation. HEK group: all media were concentrated 10 -fold by ultrafiltration.

${ }^{b}$ Input multiplicities: NDV $=100 ;$ Sindbis $=2.5$.

${ }^{c}$ Expressed as reciprocal of highest dilution protecting $50 \%$ of the cells against VSV.

TABLE 2. Sensitivity of mycoplasma-infected cultures of $L$ and $H E K$ cells to the action of interferon

\begin{tabular}{|c|c|c|c|c|c|}
\hline \multirow{2}{*}{$\begin{array}{l}\text { Cell } \\
\text { type }\end{array}$} & \multirow{2}{*}{ Infecting organism } & \multicolumn{4}{|c|}{$\begin{array}{c}\text { Titer of interferon } \\
\text { on day }\end{array}$} \\
\hline & & 0 & $3-4$ & 7 & 10 \\
\hline \multirow[t]{4}{*}{$\mathbf{L}$} & $\begin{array}{l}\text { Mycoplasma } \\
\text { F12 }\end{array}$ & 一 & 3,200 & - & 3,200 \\
\hline & M. hominis 1 & - & 6,400 & 6,400 & 1,600 \\
\hline & $\begin{array}{l}\text { Negroni } \\
\text { agent }\end{array}$ & - & 3,200 & - & 1,600 \\
\hline & None & 3,200 & - & 3,200 & 1,600 \\
\hline \multirow[t]{3}{*}{ HEK } & M. hominis 1 & - & 512 & 512 & 384 \\
\hline & $\begin{array}{l}\text { M. pneu- } \\
\text { moniae }\end{array}$ & - & 256 & 384 & 384 \\
\hline & None & 384 & - & - & 256 \\
\hline
\end{tabular}

${ }^{a}$ Expressed as reciprocal of highest dilution of NDV-induced $L$ or HeLa interferon protecting $50 \%$ of the cells against VSV. 
trols. Maximal variations in titer were of the order of $0.5 \log _{10}$, and they were unrelated to the presence of mycoplasma in the cultures and the extent of their multiplication.

\section{Discussion}

The presence of mycoplasma in cell cultures can influence the replication of viruses in a number of ways. For example, low yields may be obtained from single $\mathbf{L}$ cells infected with mengovirus (2) or the number of yielder cells themselves may be reduced as in adenovirus-infected KB cells (13). The inhibition of cytopathic effects of measles virus in HEp-2 cultures (3) and of VSV in several types of cells (1) has also been described. Furthermore, the morphological transformation of chick embryo cells induced by Rous sarcoma virus (RSV) as well as the formation of complement-fixing antigen by Rous associated virus (RAV), both processes which do not necessarily involve viral replication $(12,14)$, were profoundly affected by mycoplasma (15).

Marked visible cell injury or grossly altered metabolic function of the mycoplasma-infected cultures did not always accompany the antiviral effects observed. Thus, suppression of virus could take place in cultures which exhibited an unimpaired growth rate and cloning efficiency (2), or under conditions where cytopathology of mycoplasma was eliminated by subculture in artificial medium (15).

In an earlier study, Cantell and Paucker (4) reported that one line of HeLa cells, which was heavily (though not visibly) infected with mycoplasma, produced consistently more virusinduced interferon, and was a less effective supporter of the growth of an interferon-sensitive challenge virus, than a mycoplasma-free line of HeLa cells. It was tempting to speculate, therefore, that infection with mycoplasma may in some way have either promoted an enhanced response to viral induction of interferon or have contributed some interferon directly to the cultures. The present study shows that under the prevailing experimental conditions such a relationship could not be demonstrated. Not only did these particular strains of mycoplasma fail to initiate the formation of interferon in cells derived from two different hosts, but they did not alter in any significant way the ability of the cultures to respond to interferon-inducing stimuli or to support the replication of an interferonsensitive virus at a time when extensive multiplication of mycoplasma had occurred.

Lack of interferon production by mycoplasma in tissue cultures was recently noted also by others (16). However, according to the same re- port, the introduction of mycoplasma into chick fibroblasts did provoke higher yields of interferon on subsequent infection with Eastern or Venezuelan equine encephalitis virus than in normal cultures. The enhancing effect on interferon yields was exerted only when mycoplasmas were inoculated $24 \mathrm{hr}$ prior to virus but not earlier. On more prolonged infection with mycoplasma, the levels of virus-induced interferon were in most instances below those obtained in controls, a fact attributed by the authors to the general deterioration of the cultures. In the absence of any further information on the size of the mycoplasma inocula and their rises in titer on subsequent incubation, it is difficult to conclude that the altered behavior of mycoplasma-infected cells with respect to interferon production can actually be correlated with the establishment and progressive increase of the organisms in the cultures.

The absence of an interferon mechanism in mycoplasma-infected cultures is, furthermore, suggested by the fact that the inhibition of adenovirus in KB cells did not extend to Dengue virus (13), and that of RSV and RAV in chick embryo fibroblasts did not extend to influenza $B$ virus (15). It would appear then that, although contamination of cell cultures with mycoplasma can result in reduced viral multiplication and expression, this may not be the inevitable outcome. When viral inhibition does occur, it may be due to mycoplasma-induced effects on cell metabolism rather than to direct or indirect mediation by interferon.

\section{ACKNOWLEDGMENTS}

This investigation was supported by Public Health Service grants CA 04568 and AI 02405 from the National Cancer Institute and the National Institute of Allergy and Infectious Diseases, respectively.

Donald Armstrong was a Special Fellow ( $* 5-F 3$ CA-13,562) of the National Cancer Institute.

The capable technical assistance of Tobi Maguire is gratefully acknowledged.

\section{Literature Cited}

1. Armstrong, D., G. Henle, N. L. Somerson, AND L. HAYFLICK. 1965. Cytopathogenic mycoplasmas associated with two human tumors. I. Isolation and biological aspects. J. Bacteriol. 90:418-424.

2. Brownstein, B., AND A. F. Graham. 1961. Interaction of Mengovirus with L cells. Virology 14:303-311.

3. Butler, M., AND R. H. Leach. 1964. A mycoplasma which induces acidity and cytopathic effect in tissue culture. J. Gen. Microbiol. 34: 285-294.

4. Cantell, K., AND K. Paucker. 1963. Studies on viral interference in two lines of HeLa cells. Virology 19:81-87. 
5. Fallon, R. J., N. R. Grist, D. R. InMAN, R. M. LemcKe, G. NegronI, AND D. A. WoOds. 1965. Further studies of agents isolated from tissue cultures inoculated with human leukaemic bonemarrow. Brit. Med. J. 2:388-391.

6. Girardi, A. J., L. Hayflick, A. M. LeWIS, AND N. L. Somerson. 1965. Recovery of mycoplasmas in the study of human leukaemia and other malignancies. Nature 205:188-189.

7. Glasgow, L. A. 1965. Interferon. A review. J. Pediat. 67:104-121.

8. Grist, N. R., AND R. J. FALlon. 1964. Isolation of viruses from leukaemic patients. Brit. Med. J. 2:1263.

9. HaYflick, L. 1965. Tissue cultures and mycoplasmas. Texas Rept. Biol. Med. 23(Suppl. 1): 285-303.

10. Negroni, G. 1964. Isolation of viruses from leukaemic patients. Brit. Med. J. 1:927-929.

11. Paucker, K., K. Cantell, and W. Henle. 1962. Quantitative studies on viral interference in suspended L cells. III. Effect of interfering viruses and interferon on the growth rate of cells. Virology 17:324-334.

12. Prince, A. M. 1960. Quantitative studies on Rous sarcoma virus. VI. Clonal analysis of in vitro infections. Virology $11: 400-424$.

13. Rouse, H. C., V. H. Bonifas, and R. W. SChleSINGER. 1963. Dependence of adenovirus replication on arginine and inhibition of plaque formation by pleuropneumonia-like organisms. Virology 20:357-365.

14. RuBin, H. 1960. The suppression of morphological alterations in cells infected with Rous sarcoma virus. Virology 12:14-31.

15. Somerson, N. L., AND M. K. CoOK. 1965. Suppression of Rous sarcoma virus growth in tissue cultures by Mycoplasma orale. J. Bacteriol. 90:534-540.

16. Yershov, F. I., AND V. M. ZhDANOV. 1965. Influence of PPLO on production of interferon in virus-infected cells. Virology 27:451-453. 